\title{
A Dynamic Dust Emission Allocation Method and Holiday Profiles Applied to Emission Processing for Improving Air Quality Model Performance
}

\author{
Guanglin Jia ${ }^{1}$, Zhijiong Huang ${ }^{2 *}$, Yuanqian Xu ${ }^{1}$, Zhuangmin Zhong $^{2}$, Qinge Sha ${ }^{1}$, \\ Xiaobo Huang ${ }^{1}$, Jing Yang ${ }^{1}$, Junyu Zheng ${ }^{2,1^{*}}$ \\ ${ }^{1}$ School of Environment and Energy, South China University of Technology, University Town, Guangzhou 510006, China \\ ${ }^{2}$ Institute for Environmental and Climate Research, Jinan University, Guangzhou 510000, China
}

\begin{abstract}
An accurate depiction of temporal and spatial variations in emissions is critical in simulating air quality with atmospheric chemical transport models. Most emission processing systems typically use prescribed profiles to allocate anthropogenic emissions based on the assumptions that the temporal variance is periodical and spatial variance is time-independent. However, these assumptions are not applicable to emission sources heavily influenced by meteorology and holiday activity. In this study, we improved the temporal and spatial allocation of anthropogenic emissions by, first of all, developing a dynamic allocation method for fugitive dust that uses the negative correlation between dust emissions and precipitation, based on hourly rainfall data generated by the Weather Research and Forecasting model. Second, we employed holidayspecific profiles that were established using continuous emission monitoring system and traffic flow monitoring data to allocate power plant and on-road mobile emissions during the Spring Festival period, when human activity differs considerably from that of non-holiday periods. The new dynamic allocation method and holiday-specific profiles were applied to emissions in the Pearl River Delta region as a demonstration. Validated using a chemical transport model, this method obviously improved the model performance for periods with rainfall, with the normalized mean bias (NMB) decreasing by $6.27 \%$ for $\mathrm{PM}_{10}$ (particulate matter with a diameter of $\leq 10 \mu \mathrm{m}$ ) and $4.33 \%$ for $\mathrm{PM}_{2.5}$ (particulate matter with a diameter of $\leq 2.5 \mu \mathrm{m}$ ). The holiday simulations revealed that the holiday-specific profiles mitigated overestimations of $\mathrm{NO}_{2}, \mathrm{SO}_{2}$, and $\mathrm{PM}_{10}$ for the Spring Festival period, with the NMBs decreasing by $37.95 \%, 18.56 \%$, and $20.83 \%$, respectively. Hence, refining the allocation of emissions improved model simulation and air quality forecasting.
\end{abstract}

Keywords: Fugitive dust; Dynamic allocation; Holiday profile; Emission process.

\section{INTRODUCTION}

Atmospheric chemical transport models (CTMs) that simulate the transport and fate of atmospheric pollutants are critical tools for regulatory decision making, attainment demonstration, and air quality forecasting. However, chemical transport models are largely uncertain, mainly stemming from ambiguous model inputs and the simplified treatments of chemical and physical processes in the model's formulation (Frey and Zheng, 2002; Sax and Isakov, 2003; Bieser et al., $2011 b)$. Among the model inputs, emissions constitute one of the most critical but inconsistent sources for CTMs in terms of not only the quantity but also the spatiotemporal distribution (Russell and Dennis, 2000; Sofiev et al., 2009;

\footnotetext{
* Corresponding author.

Tel.: +86-020-37336635; Fax: 86-020-37336635

E-mail address: bmmj@163.com (Z.Huang);

zheng.junyu@gmail.com (J. Zheng)
}

Huang et al., 2017). Geng et al. (2017) demonstrated that the spatial proxies used to split the top-down emissions into gridded emission data significantly affected the simulation of $\mathrm{NO}_{2}$ columns. Also, in several studies, accurate emission allocation has been beneficial for improving air quality simulations and their applications (Gregg et al., 2009; Lindhjem et al., 2012; Yin et al., 2015). For example, Yin et al. (2015) found that updating the spatial allocation of volatile organic compound (VOC) emissions from industrial sources using location information derived from Google Earth improved ozone simulations in urban areas; it revealed that the normalized mean bias (NMB) exhibited a regionwide decrease in October by $0.1 \%$ to $4.1 \%$.

The Sparse Matrix Operator Kernel Emissions (SMOKE) modeling system developed by the MCNC Environmental Modeling Center is a widely used tool for converting an emission inventory into gridded model-ready emission data through temporal and spatial allocation and chemical speciation (Bieser et al., 2011a, b). Although this system was primarily designed to create model-ready emission for CTMs in the United States, it has been adapted to other 
regions outside the United States, including Spain (Bieser et al., 2011a), Korea (Kim et al., 2008), and the Pearl River Delta (PRD) region of China (Wang et al., 2011). During the temporal and spatial allocations, the online emission monitoring and location information (latitude and longitude) provide preferential data because they directly capture emission patterns. However, obtaining sufficient online emission observations is usually infeasible because of the large cost and huge time requirements. Therefore, the SMOKE system typically uses prescribed allocation profiles that rely on surrogate data to convert city-based/county-based annual emissions into gridded model-ready emissions.

The prescribed temporal allocation profiles use monthly, weekly, and diurnal weighting factors to allocate annual emissions to monthly, weekly, and hourly categories, respectively. Similarly, spatial allocation profiles, which describe the proportion of total city or state emissions in a grid, are used to allocate bulky city-based/county-based emissions to each grid in study domains. To accurately allocate emissions, surrogate data that are highly relevant to the emission activity are recommended to create temporal and spatial profiles (SMOKE version 3.1 User's Manual, 2012). For instance, the road network can represent spatial patterns of on-road mobile emissions and fugitive dust from road activity (Zheng et al., 2009; Fu et al., 2017), and population density can represent the spatial patterns of cooking and residential combustion emissions (Streets et al., 2003; Winijkul and Bond, 2016). The monthly emission patterns of industrial sources can be approximated by the monthly output and the use of raw materials.

A major limitation of these prescribed profiles is that they do not reflect the dynamic variations in emission sources. The SMOKE system assumes that temporal variances of anthropogenic emission sources are periodic at weekly and diurnal levels, and week-to-week variations within 1 month are ignored. In addition, spatial variances are assumed to be time-independent. For example, all Mondays in a month use the same diurnal emission profile, and all days in a month use the same spatial allocation profile. This is reasonable for emission sources with regular temporal patterns, such as industrial sources that generally have an apparent diurnal variation. However, not all sources vary regularly, especially for those influenced by meteorology and holiday activities. For example, the emission pattern of fugitive dust depends on not only land use and human activity but also rainfall variations (Kuhns et al., 2003). Moreover, changes in human activity during the Chinese National holidays (October 1-7) significantly affect the speciated profiles and chemical reactivity of VOCs in the atmosphere (Xu et al., 2017). In this case, prescribed temporal profiles and spatial surrogates are no longer applicable to such dynamic sources such as biogenic sources, fugitive dust, ammonia $\left(\mathrm{NH}_{3}\right)$ fugitives, marine sources, and biomass burning emissions. Moreover, most of these dynamic sources are primary contributors to ambient $\mathrm{PM}_{2.5}$ (Zhang et al., 2013; Karagulian et al., 2015). Therefore, an accurate temporal and spatial allocation of these dynamic sources is critical for air quality modeling and management.

In this paper, we propose a new dynamic method for the temporal and spatial allocation of fugitive dust sources. The new method considers the effect of meteorology on emissions by studying hourly rainfall in determining the allocations. In addition, temporal profiles for special holidays were developed to demonstrate the effects of holiday activity on anthropogenic emissions. We applied the new dynamic method and special holiday profiles to case studies analyzing the effect of allocation on air quality modeling in the PRD region using the Comprehensive Air Quality Model with extensions (CAMx; ENVIRON, 2011), a widely used chemical transport model that evaluates particular effects on air quality modeling.

\section{METHODS AND DATA SOURCES}

In this section, we describe a new dynamic allocation method and updated holiday-specific profiles, and then using them in the SMOKE processing system for the PRD region (SMOKE-PRD; Wang et al., 2011). The simulation was conducted using the Weather Research and Forecasting (WRF)/SMOKE-PRD/CAMx modeling system.

\section{Dynamic Allocation of Fugitive Dust Emissions}

The temporal and spatial allocation of dust sources is typically achieved by using prescribed profiles. The spatial profiles were created with a "stand road length" method that considers the road network and traffic flow with the assumption that the fugitive road dust is positively correlated with on-road mobile activities (Zheng et al., 2009). Regarding the temporal profiles, the monthly weighting factors were developed by calculating the proportion of dry days in each month to the total dry days in a year based on a road dust estimation model from the U.S. Environmental Protection Agency (EPA, 1997), and the weekly and diurnal weighting factors were developed using the averaged traffic flow (Huang et al., 2015). However, these prescribed temporal and spatial profiles have two limitations. First, the prescribed temporal profiles only account for the rainfall effects on fugitive dust at the monthly level but ignore daily and hourly rainfall. Second, the prescribed profiles portray the spatial distribution of dust emissions as time-independent, but in fact, the washout effect of rainfall does indeed affect the spatial distribution of dust emissions. These two limitations may lead to overestimation of dust emissions on a rainy day in some areas (Xuan et al., 2000).

To address these two limitations, we devised a dynamic method for allocating fugitive dust emissions by considering the washout effect of hourly precipitation. The dynamic allocation method involves two steps. First, similar to the conventional method, the top-down fugitive dust emissions were split into hourly emission grids using the prescribed temporal and spatial profiles. A uniform monthly profile was applied, and it assumed that no rainfall occurred during the entire year. This preliminary profile was necessary because the washout effect of precipitation was determined in the next step. Second, the fugitive dust emissions for each hour and each grid cell were adjusted using the precipitation correction factor, depending on the hourly gridded precipitation data simulated by the WRF model (as in Table 1). Studies have shown that emissions from unpaved roads should be 
Table 1. Correction factor based on the precipitation.

\begin{tabular}{llll}
\hline Precipitation in Hour 1 & Precipitation in Hour 2 & Correction factor in Hour 1 & Correction factor in Hour 2 \\
\hline$<0.254 \mathrm{~mm}$ & $<0.254 \mathrm{~mm}$ & 1 & 1 \\
$<0.254 \mathrm{~mm}$ & $\geq 0.254 \mathrm{~mm}$ & 1 & 0 \\
$\geq 0.254 \mathrm{~mm}$ & $\geq 0.254 \mathrm{~mm}$ & 0 & 0 \\
$\geq 0.254 \mathrm{~mm}$ & $<0.254 \mathrm{~mm}$ & 0 & 0.8 \\
\hline
\end{tabular}

set to zero when the total daily rainfall exceeds $0.254 \mathrm{~mm}$ (AP-42, Compilation of Air Emissions Factors; U.S. EPA, 1993, 1998). Following the EPA's work, we chose 0.254 $\mathrm{mm}$ as the threshold of rainfall events. Kuhns et al. (2003) found that the paved roads could remain visibly wet for at most $6 \mathrm{~h}$ after a rain shower of less than $3.5 \mathrm{~mm}$ in the winter season. Also, Bergametti et al. (2016) showed that the fugitive dust can be observed in a shorter time after rain stops $(<6 \mathrm{~h})$ in the case of light-rain events $(<2 \mathrm{~mm})$. Given the high summer temperatures in the Pearl River Delta region and the lower threshold $(0.254 \mathrm{~mm})$, we used 2 hours instead of 6 hours as the wet period length in this study. If the precipitation for each of the 2 adjacent hours was greater than $0.254 \mathrm{~mm}$, the correction factors for the current and the next hour were 0 , indicating that precipitation entirely suppressed fugitive dust emissions. If the precipitation in the next hour was less than $0.254 \mathrm{~mm}$, the correction factor for that hour was 0.8 . If the precipitation for the 2 adjacent hours was less than $0.254 \mathrm{~mm}$ for both hours, the correction factors for these 2 hours were 1, indicating a slight effect of precipitation on dust emissions. Eq. (1) describes the dynamic method for fugitive dust emissions:

$E_{i, j}^{\prime}=F_{i, j} \times \frac{T_{i} \times S_{j}}{\sum_{1}^{m} \sum_{1}^{n} T_{i} \times S_{j}} \times E_{o}$

where $E_{i j}^{\prime}$ is the reallocated emissions at grid $j$ and hour $i, E_{o}$ is the dust emissions of a city, assuming no rain that day; and $F_{i, j}$ is the precipitation correction factor at grid $j$ and hour $i$ determined by hourly precipitation data from the WRF model (Skamarock and Klemp, 2008). $T_{i}$ is the temporal allocation factor for hour $i$ according to the prescribed dayof-week and hourly profiles. $S_{j}$ is the spatial allocation factor at grid $j$ according to the prescribed spatial profile. Finally, $m$ is the total grid number covered by the city, and $n$ is the total number of hours in the simulation period.

\section{Updated Special Profiles for Holidays}

Holidays alter commercial and commuting activities and thus affect anthropogenic emissions. In the SMOKE system, the diurnal and day-of-week profiles for the weekend model the temporal pattern for holidays. Holidays are treated as weekends in the modeling system. This attempts to capture activity changes such as plant closures. In China, weekend profiles could represent the hourly emission variation during short-term holidays, but they might be invalid for long-term holidays, such as the Chinese New Year, when the largest annual human migration happens as millions of Chinese people return to their hometowns for family reunions. Therefore, some anthropogenic emissions, such as those from on-road mobile and industrial sources, might exhibit distinct temporal and spatial patterns. In this study, we also developed special profiles to exclusively represent the temporal patterns of onroad mobile sources and power plants during the Spring Festival.

\section{Emission Inventory}

This study adopted a high spatiotemporal resolution anthropogenic emission inventory of Guangdong Province (GD) from 2012 (Yin et al., 2017; Zhong et al., 2018). For the Hong Kong area in the modeling domain, annual emissions were provided by the Hong Kong Environmental Protection Department (HKEPD). The Multi-resolution Emission Inventory for China (Liu et al., 2015) developed by Tsinghua University, with the local activity data and accurate allocation information, was used to fill data gaps in the area outside GD in China. For the region outside China, the Regional Emission inventory in Asia (Ohara et al., 2007) was adopted. Biogenic VOC emissions were estimated using the Model of Emission of Gases and Aerosols from Nature (Guenther et al., 2012). Sea salt emissions were regarded as a biogenic source and estimated by a sea salt emission program (Seasalt version 3.1, http://www.camx.com).

\section{Modeling Systems}

A three-dimensional regional air quality simulation platform that integrated the WRF model, the SMOKE-PRD system (Wang et al., 2011), and the CAMx, was used to validate the new dynamic allocation method and holiday profiles. The modeling system used the Lambert conformal projection and three nested domains. The resolution of two coarse domains was $27 \mathrm{~km} \times 27 \mathrm{~km}$ (D1, covering most parts of East and Southeast Asia) and $9 \mathrm{~km} \times 9 \mathrm{~km}$ (D2, covering GD and its surroundings), and of the fine domain was $3 \mathrm{~km}$ $\times 3 \mathrm{~km}$ (D3, covering the whole PRD region and Hong Kong). The schematic diagram of the modeling domain and key parameters is illustrated in Fig. 1 and Table S1.

\section{Experimental Design}

In this study, we established a paired simulation with a base case (B-Case1) and a dust source case (D-Case1) to evaluate the new dynamic allocation methods for dust sources (Table 2). B-Case1 used the prescribed temporal and spatial profiles to allocate dust emissions, including road dust and construction dust emissions. D-Case1 was similar to B-Case1, except D-Case1 used the dynamic allocation method to process the dust source. In this paired simulation, we selected July 2013 as the simulation period because rainfall was frequent.

We also established another paired simulation of a base 


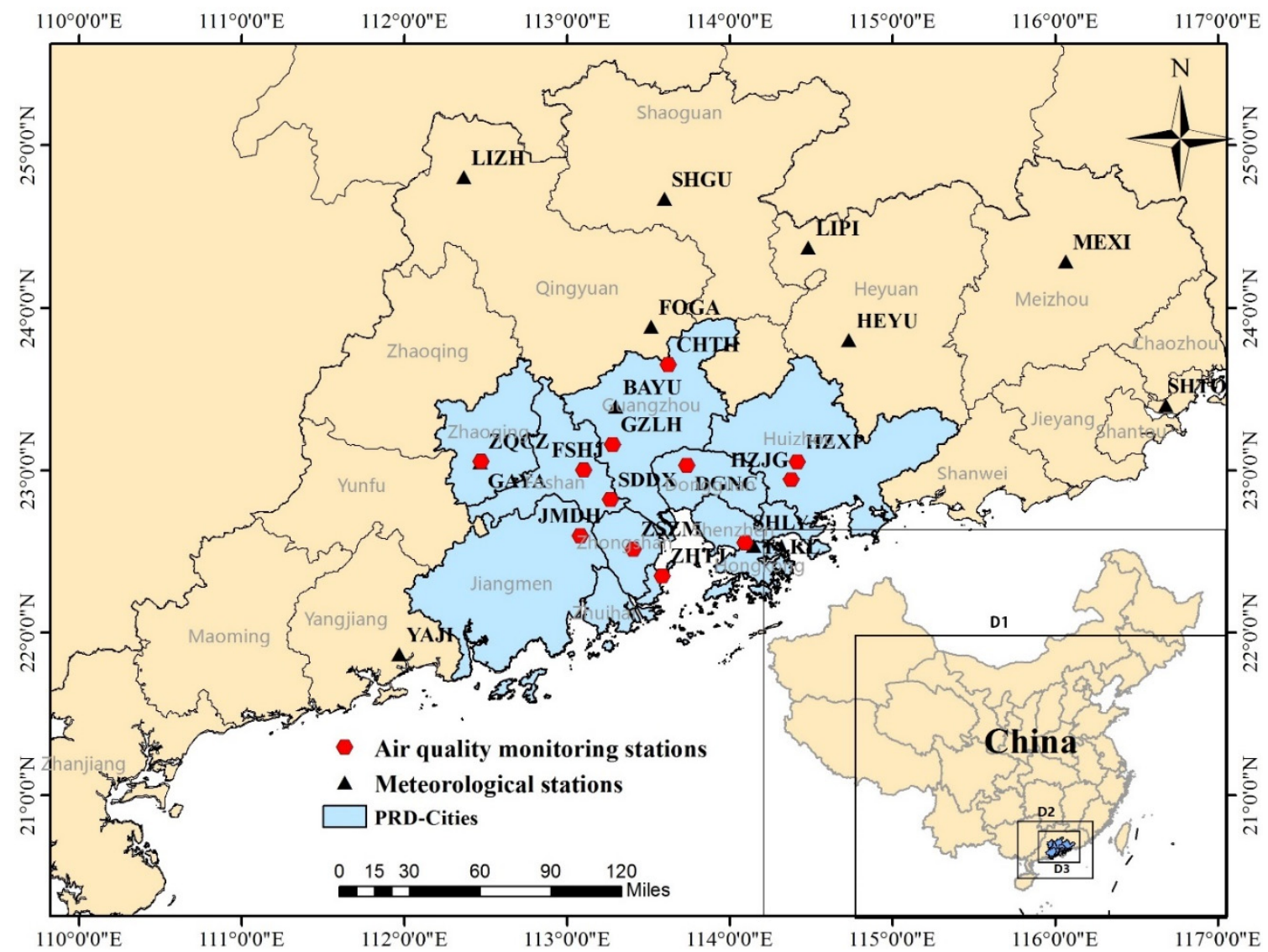

Fig. 1. Nested modeling domains configured for SMOKE-PRD system (D1: $27 \mathrm{~km} \times 27 \mathrm{~km}$; D2: $9 \mathrm{~km} \times 9 \mathrm{~km}$; D3: $3 \mathrm{~km} \times$ $3 \mathrm{~km})$.

Table 2. Allocation methods of the 4 simulation cases.

\begin{tabular}{lllll}
\hline Sectors & B-Case1 & D-Case1 & B-Case2 & H-Case2 \\
\hline Power plant & Prescribed profiles & Prescribed profiles & Prescribed profiles & Holiday profiles \\
On-road mobile & Prescribed profiles & Prescribed profiles & Prescribed profiles & Holiday profiles \\
Dust source & Prescribed profiles & Dynamic allocation & Prescribed profiles & Prescribed profiles \\
\hline
\end{tabular}

case (B-Case2) and an updated case (H-Case2) to examine the effect of the special holiday profiles on model simulation. B-Case 2 used the 2012-based emissions with the prescribed temporal and spatial profiles, whereas H-Case 2 used the 2012-based emissions with prescribed spatial surrogates but updated holiday profiles. In this paired simulation, the simulation period was the Spring Festival in 2012.

\section{Observations and Model Evaluation}

The new dynamic allocation method for determining dust emissions relies on WRF modeling data. We used meteorological observations from 11 weather stations (including 7 in the PRD region) to evaluate the performance of WRF modeling in GD. Meteorological observations included ground surface temperature, wind speed and direction, and relative humidity. Mean bias (MB), mean error (ME), NMB, $\mathrm{NME}$, and root mean square error (RMSE) were used to quantify the performance of the model (Eder and $\mathrm{Yu}, 2006$ ). The evaluation results suggested that the model system can reproduce temperature and relative humidity, but marginally overpredict wind speed with a positive MB of $0.26 \mathrm{~m} \cdot \mathrm{s}^{-1}$ and NMB of $12.11 \%$. Wind direction is a vector, and relatively high consistency was observed with an $\mathrm{MB}$ of $6.56^{\circ}$ in the PRD region. The detailed performance statistics are presented in Table S2. In general, the bias of the WRF modeling system was acceptable, and the data were used for allocation.

The CAMx model assessed the effectiveness of the new dynamic allocation method for model improvement. Therefore, we also used hourly observations from the PRD Regional Air Quality Monitoring Network (RAQMN; Zhong et al., 2013) to evaluate the CAMx model. Statistical metrics such as MB, ME, NMB, NME, and RMSE (Boylan and Russell, 2006; Borrego et al., 2008) were applied. NMB and NME are the two critical statistical metrics recommended by the U.S. EPA $(2007,2009)$ and have been frequently used to evaluate model performance in many air quality modeling studies (Smyth et al., 2009; Cho et al., 2012). All measurements in RAQMN were subject to strict quality assurance and control procedures. The evaluation results of CAMx are discussed subsequently. 


\section{RESULTS AND DISCUSSION}

\section{Temporal and Spatial Allocation of Dust Emissions}

Fig. 2 compares the daily and hourly variations in dust emissions ( $\mathrm{PM}_{10}$ was used as an example) allocated by different methods. B-Case1 used the prescribed temporal profile, and daily variation in $\mathrm{PM}_{10}$ emissions displayed a minor periodic change, completely independent of rainfall. Even during July 25 to 27 , with intensive precipitation in $\mathrm{GD}, \mathrm{PM}_{10}$ emissions from dust sources still corresponded with the normal level for the dry period, but this is not true in reality (Fig. 2(a)). This indicated that the allocation method that relied on prescribed temporal profiles could not reflect the dynamic changes in dust emissions because the washout effect on dust sources from hourly precipitation was neglected. By contrast, the daily variation in $\mathrm{PM}_{10}$ emissions allocated by the dynamic method exhibited a distinct negative linear relationship with precipitation, particularly from July 25 to 27 . The precipitation decreased $\mathrm{PM}_{10}$ emissions in the whole domain on July 26 by approximately $23 \%$, which may have profoundly affected the $\mathrm{PM}_{10}$ simulation (Fig. 2(c)). In other words, the new dynamic allocation method produced appropriate dust emissions. Figs. 2(b) and 2(c) depict the hourly variation in $\mathrm{PM}_{10}$ emissions from dust sources allocated by the prescribed profiles and the dynamic method. In the dry period, the hourly variation patterns based on the two methods were similar. Both were high in the day and low in the night. In rainy hours, dust emissions substantially decreased with the new dynamic allocation method. These comparisons suggest that the new dynamic allocation method appropriately allocated dust emissions.
The spatial difference between gridded dust emissions from the prescribed allocation profiles and the dynamic allocation method are compared in Fig. 3. Dust emissions on a dry day (July 5, 2013) and a rainy day (July 26, 2013) were used as examples. On dry days, the prescribed profiles and dynamical location method distributed dust emissions in a similar way. However, on rainy days, differences emerged. In the central and eastern PRD regions with precipitation, dust emissions were suppressed. The aforementioned regions are characterized by high dust emissions. A slight washout effect was also observed in the other region with lower dust emissions. Thus, the spatial pattern of dust sources was also reasonably depicted using the dynamic method on both rainy and dry days. No dust emission change was observed in Hong Kong because its emission data contained no dust source.

\section{Holiday Profiles for the Power Plant and On-road Mobile Sources}

Fig. 4 compares daily variations in the anthropogenic emissions allocated by the conventionally prescribed temporal profiles with those allocated by the holiday-specific profiles. Power plant and on-road mobile emissions were used as examples because power plants and on-road mobile sources are more affected by holidays than other emission sources. The prescribed temporal profiles were generally developed using the averages of surrogate data. Thus, they only represent the temporal variation in the non-holiday period. In general, during the Spring Festival, power plant emissions exhibited a distinct temporal variation from those in the non-holiday period. In the non-holiday period, power plant emissions
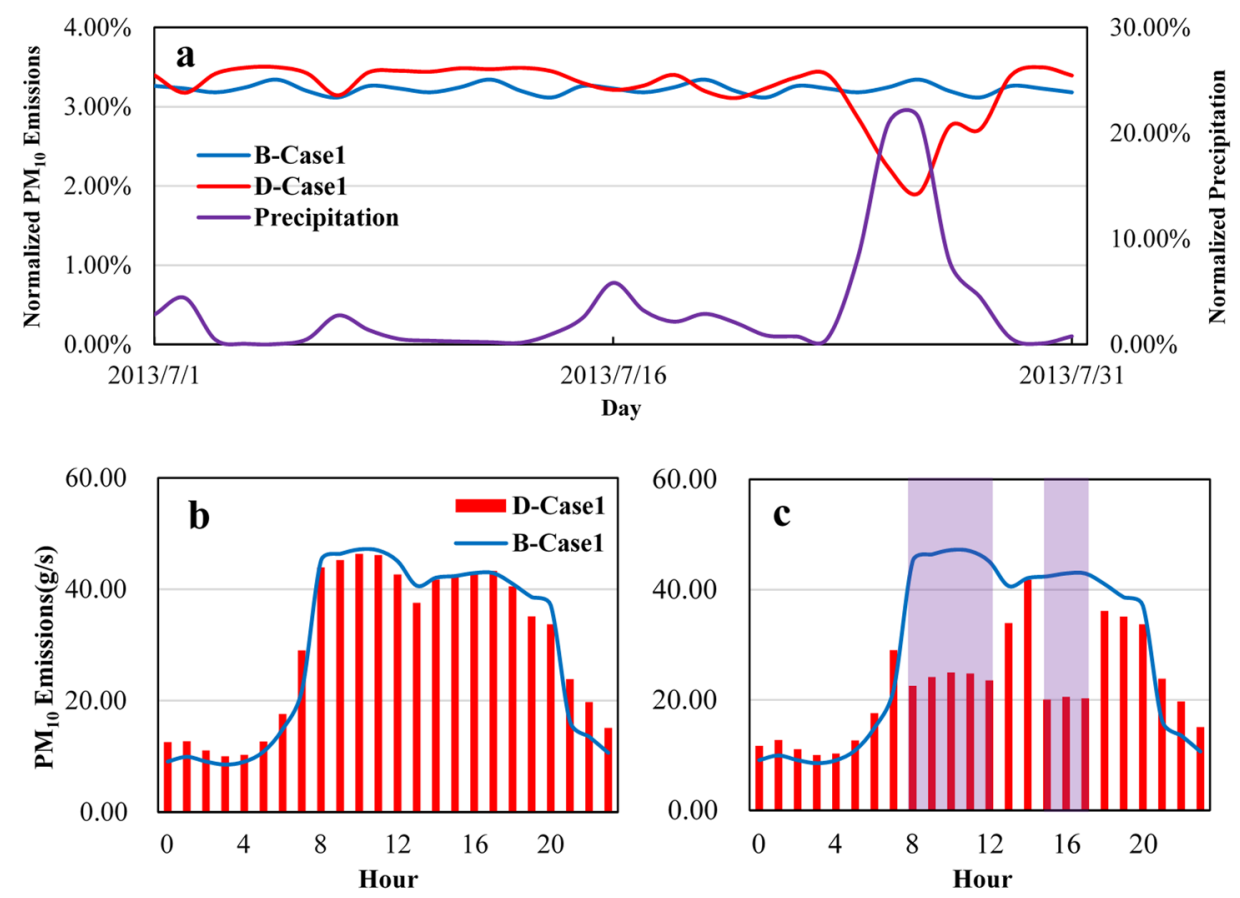

Fig. 2. (a) shows daily emission fraction (dimensionless) using the prescribed temporal profiles (blue line) and the dynamic profile (red line), and precipitation (purple line) averaged over the third domain in July 2013; (b) shows hourly variation in $\mathrm{PM}_{10}$ on a typical dry day (July 5,2013 ) in a typical grid; (c) shows hourly variation in $\mathrm{PM}_{10}$ on a typical rainy day (July 26 , 2013 ) in a typical grid, and the hour covered by the purple area indicates the precipitation over $0.254 \mathrm{~mm}$. 

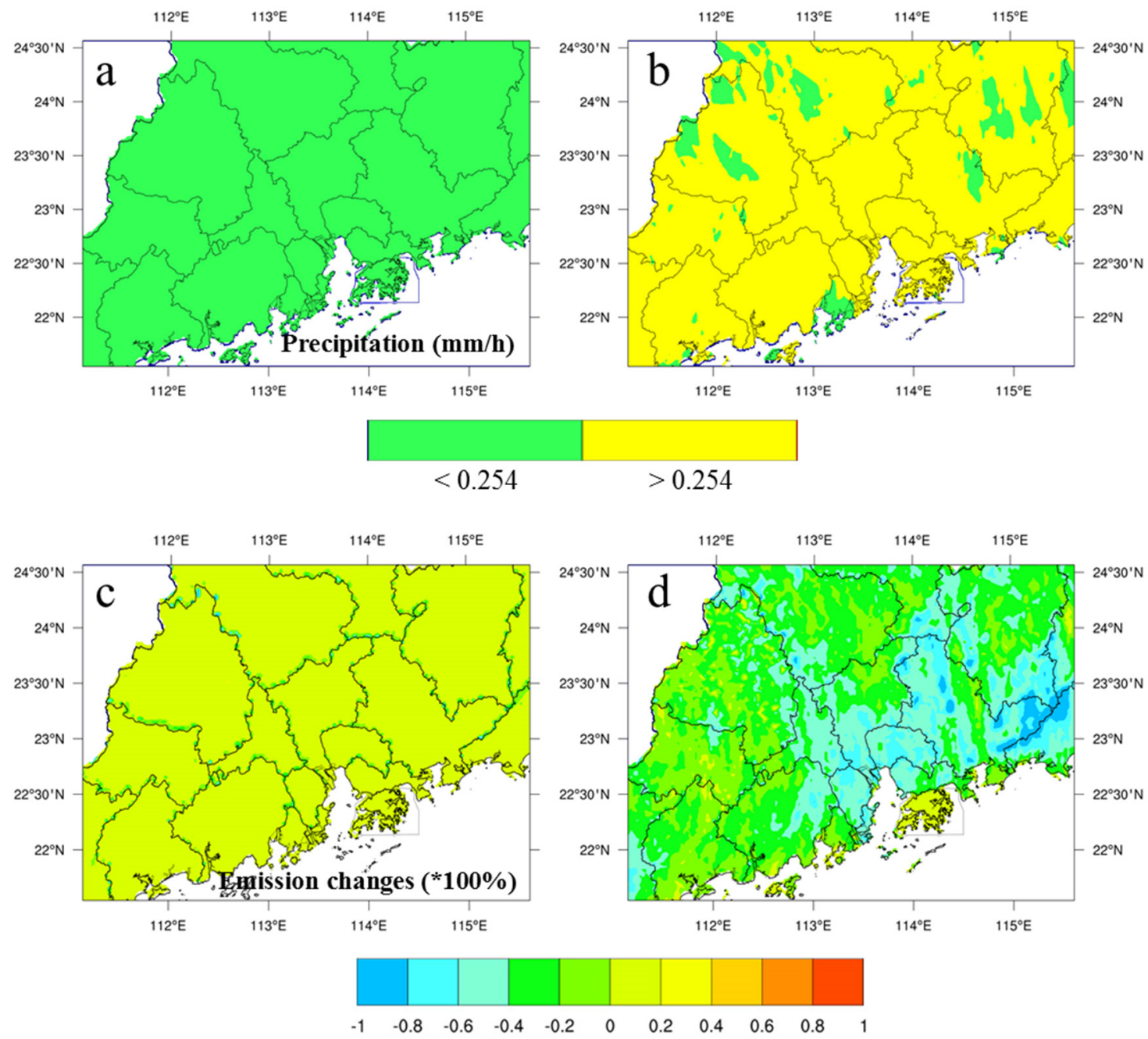

Fig. 3. (a) and (b) show the hourly precipitation on a typical dry day (July 5, 2013) and typical rainy day (July 26, 2013) in the third modeling domain; (c) and (d) show the percentage changes in $\mathrm{PM}_{10}$ from dust sources on a typical no-rain day (July 5,2013 ) and rainy day (July 26, 2013).

changed a little, whereas those emissions decreased during the Spring Festival mainly because factory shutdowns and production cuts reduced power demand during the holiday (Fig. 4(a)). However, we nonetheless observed that the highest power plant emissions occurred on January 22, 2012, during the Spring Festival, mainly because New Year's Eve celebrations held in China increased power demand.

Regarding the on-road mobile sources (Fig. 4(b)), emissions from heavy-duty vehicles (HDVs) and light-duty vehicles (LDVs) in the PRD drop significantly during the Spring Festival. This is because most people travel from megacities to their hometowns for reunions, which substantially reduces vehicle activity in urban areas (Wang et al., 2017). Therefore on-road moving vehicles have lower emissions during the Spring Festival in contrast to the normal period. In addition to the daily variation, the hourly variation in the on-road mobile sources during the Spring Festival also differed from that during non-holidays. During the Spring Festival, emissions peaked for both HDVs and LDVs in the daylight hours. Detailed information regarding hourly variation appears in Fig. S1.
Because the activity data were limited, we only developed holiday profiles for the power plant and on-road mobile sources. However, other anthropogenic sources, including industrial processes, solvent use, and cooking, might also exhibit their own specific temporal variation during holidays. For instance, Lin and Mcelroy (2011) suggested that a decline in $\mathrm{NO}_{x}$ emissions during the Spring Festival partly resulted from the decrease in industrial sources. Typically, longer holidays lead to larger changes in emissions. Therefore, to improve model simulations, developing holiday profiles for each anthropogenic source is critical.

\section{Model Performance of Different Allocation Scenarios}

In this study, two paired simulations evaluated the effects of the new dynamic allocation method and holiday profiles on model simulations. The first paired simulation, B-Case1 and D-Case1, analyzed the dynamic allocation method of dust sources. Thus, we focused on the evaluation of $\mathrm{PM}_{10}$ and $\mathrm{PM}_{2.5}$ simulation performance. The second paired simulation, B-Case2 and H-Case2, examined the holiday profiles of the power plant and on-road mobile sources. 

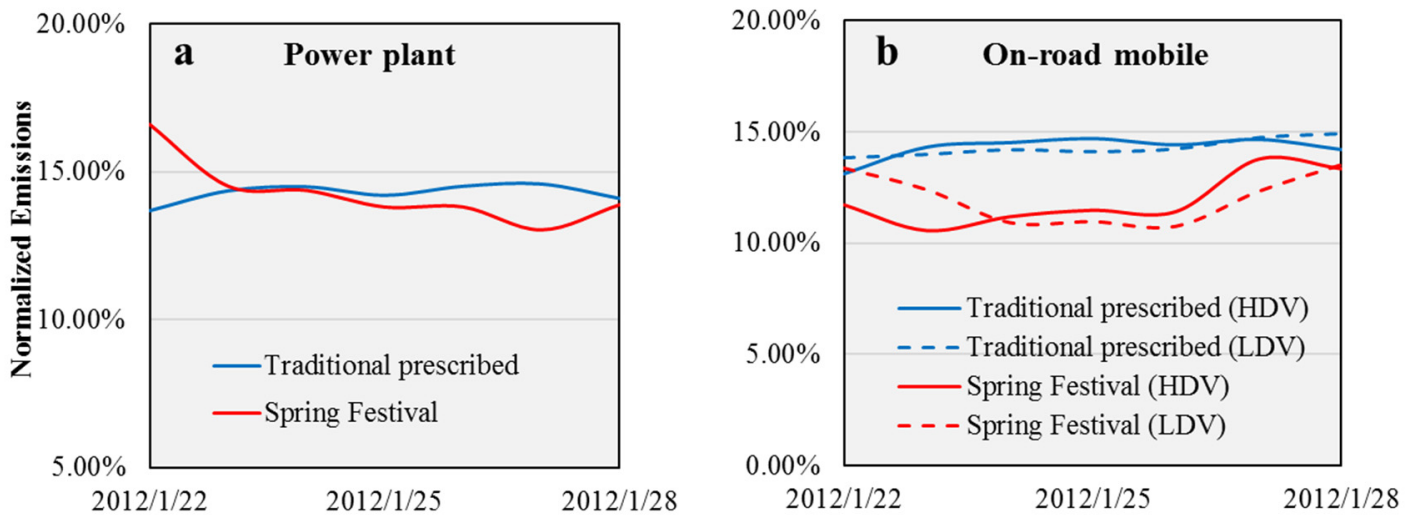

Fig. 4. Daily variation using traditionally prescribed (blue) and holiday (red) profiles.

Because the power plant was a major source of $\mathrm{NO}_{2}, \mathrm{SO}_{2}$, and $\mathrm{PM}_{10}$ emissions but on-road mobile sources were a major source of $\mathrm{NO}_{2}$ emissions, the evaluation of the second paired simulation was focused on $\mathrm{NO}_{2}, \mathrm{SO}_{2}$, and $\mathrm{PM}_{10}$.

\section{Effect of Dynamic Allocation of Fugitive Dust Emissions}

Fig. 5 compares the time series of simulated $\mathrm{PM}_{10}$ concentrations for B-Case1 and D-Case1. B-Case1 and DCase1 used the same emission dataset, but B-Case1 used the conventionally prescribed profile method, and D-Case1 used the dynamic allocation method for dust emissions. Fig. 5 only depicts simulations from July 25 to 27, when intensive precipitation occurred in the PRD region. The Guangzhou (GZLH), Zhongshan (ZSZM), Shenzhen (SZLY), and Dongguan (DGNC) sites, where dust emissions were concentrated, were selected as examples for Fig. 5.

In B-Case1, $\mathrm{PM}_{10}$ concentrations in the urban area were overestimated on rainy days. In particular, simulated $\mathrm{PM}_{10}$ concentrations at the ZSZM and GZLH stations demonstrated an abnormal peak on July 26, potentially resulting from the overestimation of primary dust emissions in this period. By contrast, in D-Case1, dust emissions largely decreased from the washout effect of precipitation, and the discrepancies between simulated and observed $\mathrm{PM}_{10}$ concentrations also decreased. The NMB of $\mathrm{PM}_{10}$ concentrations in GZLH, ZSZM, SZLY, and DGNC decreased by $25.37 \%$, 36.42\%, $8.12 \%$, and $19.47 \%$, respectively (Table 3 ), indicating that the dynamic allocation of dust emissions improved model simulations for rainfall periods. In particular, the peak of simulated $\mathrm{PM}_{10}$ concentrations at the ZSZM and GZLH sites decreased substantially. This was because the changes were mainly concentrated in the central area of the PRD region (Fig 3(d)), where the ZSZM and GZLH sites are located, indicating that dust emissions were the major contributor to $\mathrm{PM}_{10}$ concentrations in this area. Similar to $\mathrm{PM}_{10}, \mathrm{PM}_{2.5}$ simulations also demonstrated improvement at these 4 sites (Fig. S3), although the improvement was weaker than that of the $\mathrm{PM}_{10}$ simulation because the contribution of dust sources to $\mathrm{PM}_{2.5}$ emissions was less than that to $\mathrm{PM}_{10}$ emissions (Peng et al., 2013; Jiang et al., 2018).

Note that not all regions saw $\mathrm{PM}_{10}$ simulation improvement; some stations performed slightly worse. For instance, the NME slightly increased by $0.82 \%, 1.66 \%, 3.48 \%$, and $3.21 \%$ at the Foshan (FSHJ), Zhaoqing (ZQCZ), Shunde (SDDX), and Conghua (CHTH) stations, respectively (Table 3). Furthermore, the NMB increased by $7.99 \%, 2.62 \%, 8.09 \%$, and $5.60 \%$ relatively at the FSHJ, ZQCZ, SDDX, and CHTH stations, respectively. Two reasons might account for the worse performance. The first reason is associated with a large uncertainty in emissions. Compared with the conventional allocation method, the new method allocates less $\mathrm{PM}_{10}$ and $\mathrm{PM}_{2.5}$ emissions in rainfall areas and periods. Thus, the overestimation of simulated $\mathrm{PM}_{10}$ concentration, partly due to the excessive allocation of $\mathrm{PM}_{10}$ emissions, was overall alleviated during the wet period. However, $\mathrm{PM}_{10}$ concentrations in some stations were underestimated in the B-Case 1, with the NMB from $-31.46 \%$ to $-45.94 \%$. In fact, most of these stations are located in the rural areas of PRD, where emission estimations generally have large uncertainties due to the unrepresentative activity data. In this case, the new allocation method would further reduce $\mathrm{PM}_{10}$ emission, consequently leading to worse $\mathrm{PM}_{10}$ simulation. Second, we refined the temporal and spatial allocation of fugitive dust but ignored other emission sources, such as open fire combustion.

\section{Effects of Holiday Profiles}

Fig. 6 compares the time series of simulated $\mathrm{PM}_{10}$ concentrations in B-Case2 and H-Case2. B-Case2 and HCase 2 used the same emission dataset, except B-Case 2 used the conventionally prescribed temporal profile method, whereas H-Case2 used the holiday-specific profiles for the power plant and on-road mobile sources. The GZLH and DGNC sites were selected for the comparison because Guangzhou and Dongguan are major contributors to on-road mobile and power plant emissions. Statistics of model performance averaged over the whole PRD region are summarized in Table 4.

As in Table 4, B-Case2 substantially overestimated $\mathrm{NO}_{2}$, $\mathrm{SO}_{2}$, and $\mathrm{PM}_{10}$ concentrations, with NMBs of $60.77 \%$, $27.49 \%$, and $36.36 \%$, respectively. The overestimates were strongly associated with the uncertainties in the temporal allocation. In B-Case2, excessive emissions were assigned to the Spring Festival based on the conventional temporal profiles, which assumed that anthropogenic activity remained at the usual level. However, this is inappropriate because 

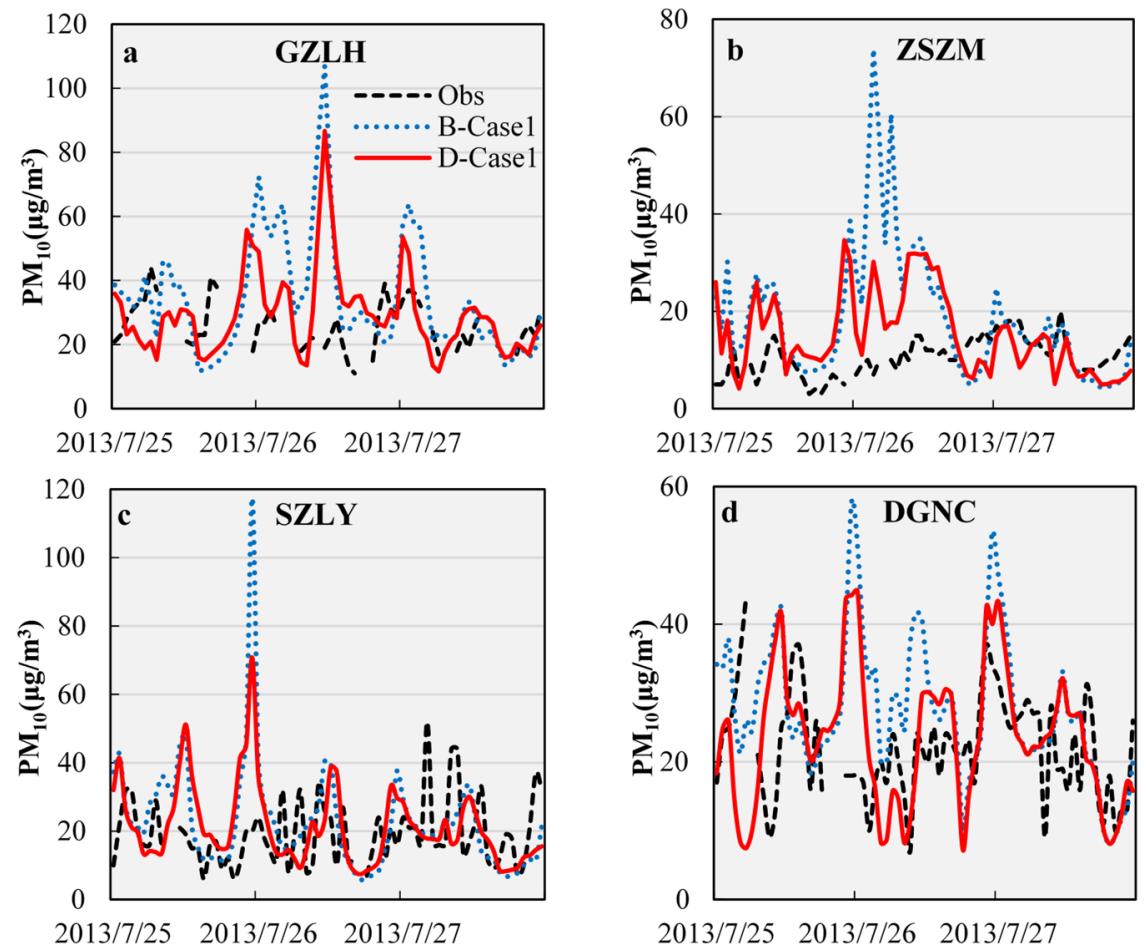

Fig. 5. Time series of simulated and observed $\mathrm{PM}_{10}$ at GZLH, ZSZM, SZLY, and DGNC from July 25 to July 27, 2013.

Table 3. The absolute differences of NMB and NME in B-Case1 and D-Case1 (July 25-27, 2013).

\begin{tabular}{|c|c|c|c|c|}
\hline \multirow{3}{*}{ Station } & \multicolumn{4}{|c|}{ D-Case1-B-Case1 } \\
\hline & \multicolumn{2}{|c|}{$\mathrm{PM}_{10}$} & \multicolumn{2}{|c|}{$\mathrm{PM}_{2.5}$} \\
\hline & $\Delta|\mathrm{NMB}|$ & $\Delta \mathrm{NME}$ & $\overline{\Delta|\mathrm{NMB}|}$ & $\Delta \mathrm{NME}$ \\
\hline CHTH & 5.60 & 3.21 & -2.63 & 0.22 \\
\hline DGNC & -19.47 & -7.23 & -7.15 & -4.50 \\
\hline FSLJ & 7.99 & 0.82 & -4.12 & -0.98 \\
\hline GZLH & -25.37 & -18.84 & 0.38 & -7.66 \\
\hline HZJG & 1.54 & 1.06 & 1.17 & 0.44 \\
\hline HZXP & 4.30 & 2.09 & -1.91 & -0.40 \\
\hline JMDH & -12.37 & -3.86 & -6.22 & -4.11 \\
\hline SDDX & 8.09 & 3.48 & -5.18 & -2.77 \\
\hline SZLY & -8.12 & -2.40 & -4.82 & -5.05 \\
\hline ZHTJ & -3.64 & -2.19 & -4.67 & -4.65 \\
\hline ZQCZ & 2.62 & 1.66 & -0.67 & 0.04 \\
\hline ZSZM & -36.42 & -25.70 & -16.15 & -11.29 \\
\hline
\end{tabular}

the massive migration from urban to rural areas suspended operations or decreased production. Using holiday-specific profiles improved model performance. Both NME and NMB decreased respectively by $22.24 \%$ and $37.95 \%$ for $\mathrm{NO}_{2}, 9.72 \%$ and $18.56 \%$ for $\mathrm{SO}_{2}$, and $20.83 \%$ and $9.67 \%$ for $\mathrm{PM}_{10}$. The improvement in urban areas with intensive mobile emissions was typically higher. As shown in Fig. 5, $\mathrm{H}$-Case2 substantially alleviated the overestimation for BCase 2 at the GZLH and DGNC stations. For example, the $\mathrm{NMB}$ in the $\mathrm{NO}_{2}$ simulation decreased by $76.11 \%$ and $65.06 \%$ at GZLH and DGNC, respectively (Table S4).

Although the holiday-specific profiles were applied, pollutant concentrations were still overestimated because other major emission sources were also highly affected by the holidays but not reflected in the simulations, such as industrial combustion, industrial processes, and solvent use. Nonetheless, we believe that the model can be further improved if holiday-specific profiles for other sources are incorporated in the case study.

The aforementioned comparisons demonstrated that holiday-specific profiles were beneficial for improving the model's performance. However, holiday-specific profiles may be spatially dependent. To investigate this, we evaluated the model performance in the rural region of the PRD (Table S4). In contrast to the urban area's stations, model performance decreased slightly in the PRD rural region. For instance, the NME and NMB of $\mathrm{PM}_{10}$ concentrations both increased at Huizhou (HZJG), with the NME increasing 

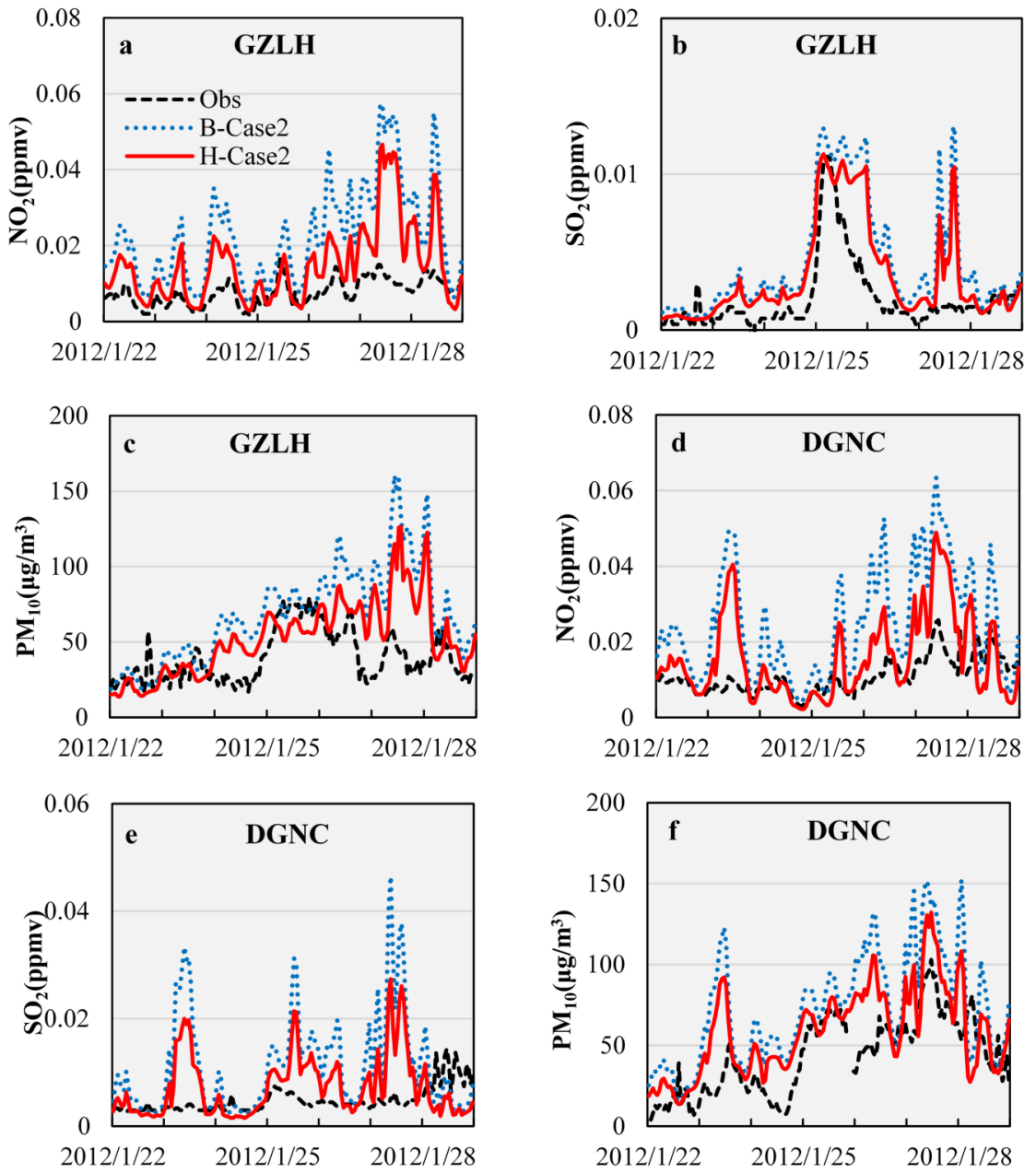

Fig. 6. Time series of simulated and observed $\mathrm{NO}_{2}, \mathrm{SO}_{2}$, and $\mathrm{PM}_{10}$ at GZLH (a-c) and DGNC (d-f) from January 22 to January 28, 2012.

Table 4. The overall model performance of CAMx in B-Case2 and H-Case2 (January 22-28, 2012).

\begin{tabular}{llllllll}
\hline & \multicolumn{3}{c}{$\mathrm{B}-$ Case2 } & & \multicolumn{3}{c}{$\mathrm{H}-$ Case2 } \\
\cline { 2 - 4 } \cline { 7 - 8 } & $\mathrm{NO}_{2}$ & $\mathrm{SO}_{2}$ & $\mathrm{PM}_{10}{ }^{\mathrm{a}}$ & & $\mathrm{NO}_{2}$ & $\mathrm{SO}_{2}$ & $\mathrm{PM}_{10}{ }^{\mathrm{a}}$ \\
\hline NMB (\%) & 60.77 & 27.49 & 36.36 & & 22.83 & 8.93 & 15.53 \\
NME (\%) & 78.63 & 81.91 & 57.19 & & 56.40 & 72.19 & 47.51 \\
RMSE (ppb) & 13.04 & 4.47 & 32.35 & & 11.64 & 3.98 & 29.60 \\
R & 0.62 & 0.29 & 0.47 & & 0.69 & 0.31 & 0.51 \\
\hline
\end{tabular}

${ }^{\mathrm{a}} \mu \mathrm{g} \mathrm{m}{ }^{-3}$.

from $51.77 \%$ to $52.35 \%$ and NMB from $11.48 \%$ to $12.87 \%$. This is possible because the holiday-specific profiles developed from the monitoring data in urban PRD areas may not match the emission variation in rural PRD areas, particularly for the on-road mobile sources. During the Spring Festival, numerous migrants leave the urban PRD areas in vehicles and return to their hometowns to celebrate the holiday. Therefore, during this festival, vehicle emissions in rural PRD areas or non-PRD cities might increase.

\section{CONCLUSIONS}

In this study, we developed a novel dynamic allocation method for fugitive dust and updated holiday-specific profiles to improve the temporal and spatial allocation of anthropogenic emissions. Unlike the conventional allocation method, which relies on prescribed profiles for which temporal and spatial variations in anthropogenic emissions are assumed to be periodical and time-independent, the new method used hourly rainfall data and addressed the washout effect of rain to refine the allocation. Applying our new approach to our case study in the PRD, the estimated dust emissions on rainy days were reduced by approximately $23 \%$, and the $\mathrm{PM}_{10}$ simulation bias was reduced by approximately $10 \%$ on average, indicating that this method is more accurate than previous ones in allocating dust emissions. 
Furthermore, we created unique local temporal profiles for power plant and on-road mobile sources to characterize emission variations during specific holidays, such as the Spring Festival. The model evaluations revealed that such profiles for the Spring Festival mitigated the overestimation of $\mathrm{NO}_{2}, \mathrm{SO}_{2}$, and $\mathrm{PM}_{10}$, significantly reducing the NME by $22.24 \%, 9.27 \%$, and $9.67 \%$, respectively. These results indicate that special local holiday profiles should be developed to improve the accuracy of air quality modeling.

The concept of dynamic emission allocation proposed in this study can also be adapted to other anthropogenic sources, such as fugitive ammonia emissions, which are greatly affected by meteorological parameters. However, accurate spatial and temporal emission allocations require a significant amount of dynamic data that reflect the spatial and temporal characteristics of emission sources. Big data may facilitate higher resolutions of spatial and temporal allocations, and our study serves as an example to initiate this type of research.

\section{ACKNOWLEDGMENTS}

This work was supported by the National Key R\&D Program of China (No. 2018YFC0213904).

\section{SUPPLEMENTARY MATERIAL}

Supplementary data associated with this article can be found in the online version at http://www.aaqr.org.

\section{REFERENCE}

Adelman, Z. and Baek, B.H. (2012). Methods for estimating meteorology-based emissions temporal profiles for livestock and residential wood combustion sources. Institute for the Environment. University of North Carolina at Chapel Hill. pp. 1-25.

Amato, F., Alastuey, A., Rosa, J. De, Castanedo, Y.G., Campa, A.M.S. and De, Pandolfi, M. (2014). Trends of road dust emissions contributions on ambient air particulate levels at rural, urban and industrial sites in southern Spain. Atmos. Chem. Phys. 14: 3533-3544.

Bergametti, G., Rajot, J.L., Pierre, C., Bouet, C. and Marticorena, B. (2016). How long does precipitation inhibit wind erosion in the Sahel? Geophys. Res. Lett. 43: 6643-6649.

Bieser, J., Aulinger, A., Matthias, V., Quante, M. and Builtjes, P. (2011a). SMOKE for Europe-adaptation, modification and evaluation of a comprehensive emission model for Europe. Geosci. Model Dev. Discuss. 3: 949-1007.

Bieser, J., Aulinger, A., Matthias, V., Quante, M. and Denier van der Gon, H.A.C. (2011b). Vertical emission profiles for Europe based on plume rise calculations. Environ. Pollut. 159: 2935-2946.

Borrego, C., Monteiro, A., Ferreira, J., Miranda, A.I., Costa, A.M., Carvalho, A.C. and Lopes, M. (2008). Procedures for estimation of modelling uncertainty in air quality assessment. Environ. Int. 34: 613-620.

Boylan, J.W. and Russell, A.G. (2006). PM and light extinction model performance metrics, goals, and criteria for three-dimensional air quality models. Atmos. Environ. 40: 4946-4959.

Chen, J.H., Wang, W., Liu, H.J. and Ren, L.H (2012). Determination of road dust loadings and chemical characteristics using resuspension. Environ. Monit. Assess. 184: 1693-1709

Cho, S., Mceachern, P., Morris, R., Shah, T. and Johnson, J. (2012). Emission sources sensitivity study for groundlevel ozone and $\mathrm{PM}_{2.5}$ due to oil sands development using air quality modeling system: Part I-model evaluation for current year base-case simulation. Atmos. Environ. 55: 533-541.

Eder, B. and Yu, S. (2006). A performance evaluation of the 2004 release of Models-3 CMAQ. Atmos. Environ. 40: 4811-4824.

ENVIRON (2011). User's guide-Comprehensive air quality model with extensions-Version 5.40. Novato.

Frey, H.C. and Zheng, J. (2002). Quantification of variability and uncertainty in air pollutant emission inventories: Method and case study for utility $\mathrm{NO}_{\mathrm{x}}$ emissions. J. Air Waste Manage. Assoc. 52: 1083-1095.

Fu, M., Kelly, J.A. and Clinch, J.P. (2017). Estimating annual average daily traffic and transport emissions for a national road network: A bottom-up methodology for both nationally-aggregated and spatially-disaggregated results. J. Transp. Geogr. 58: 186-195.

Geng, G., Zhang, Q., Martin, R. V., Lin, J., Huo, H., Zheng, B., Wang, S. and He, K. (2017). Impact of spatial proxies on the representation of bottom-up emission inventories: A satellite-based analysis. Atmos. Chem. Phys. 17: 41314145.

Gregg, J.S., Losey, L.M., Andres, R.J., Blasing, T.J. and Marland, G. (2009). The temporal and spatial distribution of carbon dioxide emissions from fossil-fuel use in North America. J. Appl. Meteorol. Climatol. 48: 2528-2542.

Guenther, A.B., Jiang, X., Heald, C.L., Sakulyanontvittaya, T., Duhl, T., Emmons, L.K. and Wang, X. (2012). The Model of Emissions of Gases and Aerosols from Nature version 2.1 (MEGAN2.1): An extended and updated framework for modeling biogenic emissions. Geosci. Model Dev. 5: 1471-1492.

Huang, Z.J., Wang, S.S., Zheng, J.Y., Yuan, Z.B., Ye, S.Q. and Kang, D.W. (2015). Modeling inorganic nitrogen deposition in Guangdong province, China. Atmos. Environ. 109: 147-160.

Huang, Z.J., Hu, Y.T., Zheng, J.Y., Yuan, Z.B., Russell, A.G. and Ou, J.M. (2017). A new combined stepwisebased high-order decoupled direct and reduced-form method to improve uncertainty analysis in $\mathrm{PM}_{2.5}$ simulations. Environ. Sci. Technol. 51: 3852-3859.

Jiang, N., Dong, Z., Xu, Y.Q., Yu, F., Yin, S.S., Zhang, R.Q. and Tang, X.Y. (2018). Characterization of $\mathrm{PM}_{10}$ and $\mathrm{PM}_{2.5}$ Source profiles of fugitive dust in Zhengzhou, China. Aerosol Air Qual. Res. 18: 314-319.

Karagulian, F., Belis, C.A., Dora, C.F.C., Prüss-Ustün, A.M., Bonjour, S., Adair-Rohani, H. and Amann, M. (2015). Contributions to cities' ambient particulate matter (PM): A systematic review of local source contributions at global level. Atmos. Environ. 120: 475-483. 
Kim, S.T., Moon, N.K. and Byun, D.W.W. (2008). Korea emissions inventory processing using the US EPA's SMOKE system. Asian J. Atmos. Environ. 2: 34-46.

Kuhns, H., Etyemezian, V., Green, M., Hendrickson, K., McGown, M., Barton, K. and Pitchford, M. (2003). Vehicle-based road dust emission measurement-Part II: Effect of precipitation, wintertime road sanding, and street sweepers on inferred $\mathrm{PM}_{10}$ emission potentials from paved and unpaved roads. Atmos. Environ. 37: 45734582.

Lin, J.T. and Mcelroy, M.B. (2011). Detection from space of a reduction in anthropogenic emissions of nitrogen oxides during the Chinese economic downturn. Atmos. Chem. Phys. 11: 8171-8188.

Lindhjem, C.E., Pollack, A.K., DenBleyker, A. and Shaw, S.L. (2012). Effects of improved spatial and temporal modeling of on-road vehicle emissions. J. Air Waste Manage. Assoc. 62: 471-484.

Liu, F., Zhang, Q., Tong, D., Zheng, B., Li, M., Huo, H. and He, K.B. (2015). High-resolution inventory of technologies, activities, and emissions of coal-fired power plants in China from 1990 to 2010. Atmos. Chem. Phys. 15: 1329913317.

Ohara, T., Akimoto, H., Kurokawa, J., Horii, N., Yamaji, K., Yan, X. and Hayasaka, T. (2007). An Asian emission inventory of anthropogenic emission sources for the period 1980-2020. Atmos. Chem. Phys. 7: 4419-4444.

Peng, K., Yang, Y., Zheng, J.Y., Yin, S.S., Gao, Z.J. and Huang, X.B. (2013). Emission factor and inventory of paved road fugitive dust sources in the Pearl River Delta region. Acta Sci. Circumst. 33: 2657-2663 (In Chinese).

Russell, A. and Dennis, R. (2000). NARSTO critical review of photochemical models and modeling. Atmos. Environ. 34: 2283-2324.

Sax, T. and Isakov, V. (2003). A case study for assessing uncertainty in local-scale regulatory air quality modeling applications. Atmos. Environ. 37: 3481-3489.

Skamarock, W.C. and Klemp, J.B. (2008). A time-split nonhydrostatic atmospheric model for weather research and forecasting applications. J. Comput. Phys. 227: 34653485.

SMOKE v3.1 User's Manual (2012) The Institute for the Environment-The University of North Carolina at Chapel Hill.

Smyth, S.C., Jiang, W., Roth, H., Moran, M.D., Makar, P.A., Yang, F., Bouchet, V.S. and Landry, H. (2009). A comparative performance evaluation of the AURAMS and CMAQ air-quality modeling systems. Atmos. Environ. 43: 1059-1070.

Sofiev, M., Miranda, A.L. and Sokhi, R. (2009). Review of the capabilities of meteorological and chemistry-transport models for describing and predicting air pollution episodes. COST 728/WMO Joint Report. 1502.

Streets, D.G., Bond, T.C., Carmichael, G.R., Fernandes, S.D., Fu, Q., He, D., Klimont, Z., Nelson, S.M., Tsai, N.Y., Wang, M.Q., Woo, J. and Yarber, K.F. (2003). An inventory of gaseous and primary aerosol emissions in Asia in the year 2000. J. Geophys. Res. 21: 8809.

U.S. EPA (1993, 1998). AP-42, Compilation of air pollutant emission factors. U.S. EPA's emission factor guidance document AP-42. U. S. Environmental Protection Agency.

U.S. EPA (2007). Guidance on the use of models and other analyses for demonstrating attainment of air quality goals for guidance on the use of models and other air quality goals for ozone, $\mathrm{PM}_{2.5}$, and Regional Haze. Air Quality Analysis Division, Air Quality Modeling Group, Office of Air Quality Planning and Standards, U.S. Environmental Protection Agency, Research Triangle Park, North Carolina.

U.S. EPA (2009). Guidance on the development, evaluation, and application of environmental models. Office of Research and Development, U.S. Environmental Protection Agency.

Wang, C., Huang X., Zhu, Q., Cao, M.L., Zhang, B. and He, L.Y. (2017). Differentiating local and regional sources of Chinese urban air pollution based on the effect of the Spring Festival. Atmos. Chem. Phys. 17: 9103-9114.

Wang, S.S., Zheng, J.Y., Fu, F., Yin, S.S. and Zhong, L.J. (2011). Development of an emission processing system for the Pearl River Delta Regional air quality modeling using the SMOKE model: Methodology and evaluation. Atmos. Environ. 45: 5079-5089.

Winijkul, E. and Bond, T.C. (2016). Emissions from residential combustion considering end-uses and spatial constraints: Part II, emission reduction scenarios. Atmos. Environ. 124: 1-11.

Xu, Z., Huang, X., Nie, W., Chi, X., Xu, Z., Zheng, L., Sun, P. and Ding, A. (2017). Influence of synoptic condition and holiday effects on VOCs and ozone production in the Yangtze River Delta region, China. Atmos. Environ. 168: 112-124

Xuan, J., Liu, G. and Du, K. (2000). Dust emission inventory in Northern China. Atmos. Environ. 34: 45654570.

Yin, S.S., Zheng, J.Y., Lu, Q., Yuan, Z.B., Huang, Z.J., Zhong, L.J. and Lin, H. (2015). A refined 2010-based VOCs emission inventory and its improvement on modeling regional ozone in the Pearl River Delta Region, China. Sci. Total Environ. 514: 426-438.

Yin, X.H., Huang, Z.J., Zheng, J.Y., Yuan, Z.B., Zhu, W.B., Huang, X.B. and Chen, D.H. (2017). Source contributions to $\mathrm{PM}_{2.5}$ in Guangdong province, China by numerical modeling: Results and implications. Atmos. Res. 186: 6371.

Zhang, R., Jing, J., Tao, J., Hsu, S.C., Wang, G., Cao, J., Lee, C.S.L., Zhu, L., Chen, Z., Zhao, Y. and Shen, Z. (2013). Chemical characterization and source apportionment of $\mathrm{PM}_{2.5}$ in Beijing: Seasonal perspective. Atmos. Chem. Phys. 13: 7053-7074.

Zheng, J.Y., Che, W.W., Wang, X.M., Louie, P.K.K. and Zhong, L.J. (2009). Road-network-Based spatial allocation of on-road mobile source emissions in the Pearl River Delta region, China, and comparisons with populationbased approach. J. Air Waste Manage. Assoc. 59: 14051416.

Zhong, L.J., Louie, P.K.K., Zheng, J.Y., Wai, K.M., Ho, J.W.K., Yuan, Z.B., Lau, A.K.H., Yue, D.L. and Zhou, Y. (2013). The pearl river delta regional air quality 
monitoring network-regional collaborative efforts on joint air quality management. Aerosol Air Qual. Res.13: 1582-1597.

Zhong, Z.M., Zheng, J.Y., Zhu, M.N., Huang, Z.J, Zhang, Z.W., Jia, G.L., Wang, X.L., Bian, Y.H., Wang, Y.L. and Li, N. (2018). Recent developments of anthropogenic air pollutant emission inventories in Guangdong province,
China. Sci. Total Environ. 627: 1080-1092.

Received for review, April 1, 2019

Revised, July 7, 2019

Accepted, September 2, 2019 